\title{
ANALYSIS OF SECURITY ISSUES FOR MOBILE CLOUD COMPUTING
}

\author{
Senthamarai R \\ Assistant Professor \\ Department of Computer Science \\ Dharmapuram Adhinam Arts College, \\ Dharmapuram, Mayiladuthurai Dt. \\ Tamilnadu
}

\begin{abstract}
Now-a-days a huge improvement of ultimate innovation hits the mobile telecommunication and wireless mechanism. In olden days people use mobile phones only for dialing and receiving calls and for exchanging messages. But, In this era they use the mobile phones not only for dialing and receiving calls but want their wireless devices to be act as a multipurpose device. To fulfill the need of the users, the developers built a Smartphone. Smartphone really are too fast and provides efficient way for calling, chatting, browsing and so on as the PC's does. The user's data stored in the mobiles are being transferred to the cloud. This happens outside the mobile devices. However, the users have certain issues with the cloud. They want their data to be stored in highly secured manner. But the data confidentiality, integrity and authenticity protection in cloud is very challenging. In this paper, we discuss some of the security issues in Mobile Cloud Computing.
\end{abstract}

Keywords: Mobile computing, Cloud computing, Mobile Cloud Computing, Wireless network, Smartphone, Cryptography.

\section{INTRODUCTION}

In recent years, both mobile computing and cloud computing are combined together and named as mobile cloud computing (MCC). One of the few security problems in Mobile Cloud Computing is very low security. Plenty of wireless devices such as mobile phones, laptop, and etc., are used for multidimensional work. Each and every user needs secure transmissions of data while using Smartphone or other communication devices. The mobile cloud computing is the mechanism for transferring data from mobile devices to the cloud via network (internet). The mobile cloud computing is not $100 \%$ secure. Several number of issues have been identified from the stakeholders all over the world. Mobile cloud computing is very

\author{
Nivetha K S \\ Student, II Year B.E. \\ Department of Computer Science and Engg. \\ Sri Venkateswara College of Engineering \\ Sriperumputhur, Kancheepuram Dt. \\ Tamilnadu
}

useful in various fields such as medical, education, entertainment etc.

\section{MOBILE CLOUD COMPUTING}

"Mobile computing is a mechanism that allows transmission of data through the wireless devices without physical network'.

Vaquero et al.(2009) have delivered "clouds are a large pool of easily usable and accessible virtualized resources (such as hardware, development platforms). These resources can be dynamically reconfigured to adjust to a variable load, allowing also for an optimum resource utilization".

"The illusion of infinite computing resources; the elimination of an up-front commitment by cloud users; and the ability to pay for use as needed" is the key characteristics of cloud computing provided by California Berkeley university.

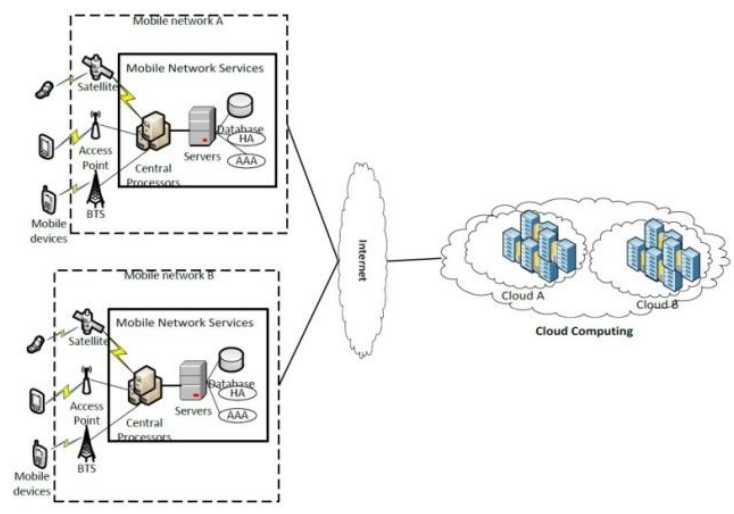

Fig.1 Mobile Cloud Computing (MCC) Architecture

The mobile cloud computing architecture is shown in fig.1. This architecture consists of several layers to give worthy services. Wireless devices are linked to wireless networks through the base station like transceiver, which is pretty good 
in developing connections between the wireless networks and wireless devices. End users transmitted the data into processing units that are associated to cloud. In mobile cloud computing, request and response methods are performed. For example end user wants to transmit their data from their wireless devices into servers. Wireless network administrators can give services of Authentication, confidentiality and integrity through the home agent and wireless device user's data stored in cloud.

\section{WIRELESS DEVICES}

There is no specialized separation of wireless devices, by size, shape, weight of computing power. Schiller et al.(2000) have stated "some wireless devices are Sensor, Embedded controllers, pager, mobile phones, personal digital assistant(PDA), pocket computer, notebook/laptop".

\section{ISSUES IN CLOUD SECURITY}

The clients have been finding out more security issues in the platform of mobile cloud computing. User's privacy is the most significant part which is supposed to be protected with high security. But it's comes under one of the notable issues of mobile cloud computing. The user generates more number of data to share with others and consume more number of data that was being shared by others. All of these data are stored in the cloud.

Many of the mobile devices have been kept attacking by the programs like virus, malware, worms, etc. However, cloud vendors give possible securities, these kind of attacking aren't going down and would have results in installing some applications to protect our devices against these attacks which may probably results in storage issues.

And the most significant problem is cloud structure. It is very challenging to store one's data into the cloud without loss and to connect all the wireless devices without interference in the cloud database.

User can access the data through any wireless devices from cloud, At that time intruder interfere and insert some unwanted data into customer applications.

Another problem is it can't be act as a proper distributor. It is complicated in Cloud to distribute the data from one device to another device.
Many wireless devices have small power backup. So many devices catch attack from power problem during the transmission.

All mobile device's performance are (full or part of data) watched and the person's information are misused by the third party.

A certain threats affect mobile cloud computing. Kim et al. (2012)[3] describe "the mobile cloud security issues associated to hostile coding shoot in a cloud domain".

Communication channel is affected from less bandwidth, high seek time and less amount of resources.

\section{RISKS IN CLOUD}

However, the cloud is having its legitimate customers and cloud organization administrators, certain staff members who are working for cloud have been trying to get and misuse the customer data. Data security problem differ from one environment to another and varies from one person to other. All users store their information such as photos, videos and important documents which would have stolen by the illegal user or some internal staff.

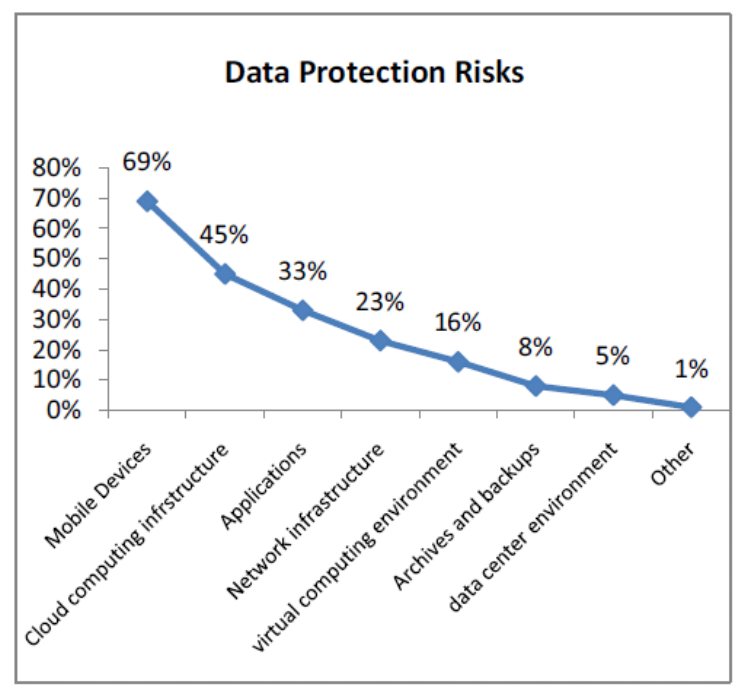

Fig.2. Potential risk of information

\section{ADVANTAGES}

A. End users can store and retrieve the data from anywhere at anytime through cloud repository.

B. User can access data of different fields from cloud.

C. Mobile cloud computing is less expensive. They provide users with pay-and-use technique. So that 


\section{International Journal of Engineering Applied Sciences and Technology, 2020 Vol. 5, Issue 1, ISSN No. 2455-2143, Pages 474-477 \\ Published Online May 2020 in IJEAST (http://www.ijeast.com)}

many clients have interests in utilizing Mobile cloud computing.

D. Cloud computing supports various kinds of platform which helps the customer to run their applications on multiple platforms.

E. Mobile cloud computing vendors provide maximum amount of memory for data storage.

F. Many business organization utilize mobile cloud computing as a valuable platform for example movie tickets, flight tickets and all mode of transport tickets has been booked in online through internet without moving to the respective firm using many advanced application. Hereby, people save their time.

\section{APPLICATIONS}

\section{Virtual reality:}

In this digital world Smartphone have sensor facility for the security of devices. Google Glass can enlarge virtual reality such as reading books or news for visually challenged person.

\section{Medical field:}

Numerous amount of patient's particular have been stored in the cloud database. This databases are being used by the doctor for further treatment at anytime and anywhere through any wireless devices.

\section{Location based services:}

This service supplies the information according to the client's location. They are "followon-services, location aware services, privacy, information services, support services".

\section{Education:}

Mobile learning (m-learning) is very useful to all kind of learners. Any type of data and information can be accessed from cloud at the minimal amount of time. Huge amount of educational stuffs have been stored in cloud. Nowa-days online classes are conducted through various applications such as Zoom, Google Meet, Google Classroom etc., and online courses are applicable in plenty of applications such as Coursera, Udemy, Alison and so on. Through these applications students and learners can watch and access the materials on the cloud.

\section{Vehicles:}

Now-a-days vehicles are equipped with multiple applications like music system, for hearing news, to know whether reports, to update road conditions and broadcast information through digital audio broadcasting (DAB) with 1:5 Mbits/s.

\section{Social Media:}

This application permits a user or group of users to share the multimedia data such as text, audio, video, animated image to others. Mobile cloud computing is playing a major role in social media.

\section{Entertainment:}

Mobile gaming is one of the briskly evolving fields. Wireless gaming is not only for entertainments, it also earns money. Movies, Series can be watched or downloaded from the cloud through internet in any language.

\section{CONCLUSION}

Mobile Cloud Computing offers a significant usage among the users of mobile devices that is enables the user to store their information in cloud. Security is one of the major concerns when the intimate details is put away and moved over the web. It is very essential to ensure that the information is assured about security. In this paper, we delivered our thoughts about Mobile Cloud Computing issues and their requirements for the security of information by understanding many books, research paper and our own experience.

\section{FUTURE WORK}

The ultimate aim of this research paper is to identify the security issues of mobile cloud computing. Cryptography ensures the confidentiality, authentication, availability, and integrity of the data. This is done through cryptographic algorithms such as Data Encryption Standard (DES), and Advanced Encryption Standard (AES). In future we can use encryption techniques in such a way that it can assure secure data transfer and data storage.

\section{REFERENCES}

[1] Vaquero L.M., and Rodero L - Merino, Caceres J, and Lindner M. (2009). A break in the clouds: Towards a cloud definition, SIGCOMM computer communications Review, 39.(pp. 50-55)

[2] Milon Biswas and Whaiduzzaman Md. (2019), Efficient mobile cloud computing through computation offloading, International Journal of Advancements in Technology, ISSN:0976-4860, Volume 10, Issue 1. 


\section{International Journal of Engineering Applied Sciences and Technology, 2020 Vol. 5, Issue 1, ISSN No. 2455-2143, Pages 474-477 \\ Published Online May 2020 in IJEAST (http://www.ijeast.com)}

[3] Pallavi Kulkarni and Dr.Rajashrikhanai. (2016), Security Frameworks for mobile cloud computing: A Sruvey., ICEEOT, DOI:10.1109. (pp. 25072511).

[4] Vikas kottari, Vishwanath kamath G, Lloyed Presley Saldanha and Chandan Mohan. (2013), A survey of mobile cloud computing : Concept, Applications and challenges, Vikas kottari et al./IJAIR, ISSN:2278-7844, Volume -2 Issue - 3, (pp. 487-492)

[5] Knoes C, Bhattachargee P K and Bhunia C T, and Maulik U. (2019), A Novel approach for Authentication technique in mobile communication, International Journal of computer theory and engineering, 1793-8201 Volume - 1, No:3 (pp. 216-221)

[6] Manish Kumar Aery. (2016), Mobile cloud computing: Security issues and Challenges, IJARCS, ISSN:0976-5697, Volume - 7, No.3 (pp. 191-194).

[7] Hoang T. Dinh, Chonho Lee, Durit Niyalo and Ping Wang. (2011), A survey of mobile cloud computing architecture, applications and approaches, Wireless communication and mobile computing 2013:13: DOI:10.1002/wcm.1203 (pp. 1587-1611).

[8] Zohreh Sanaei, Saeid Abolfazili, Abdullah Gani, and Rajkumar Buyya (2013), Heterogeneity in mobile cloud computing : Taxonomy and open challenges, IEEE, DOI:10.1109/ SURV. 2013.050113.00090, Volume - 16, Issue - 1 (pp. 369-392).

[9] Mahendra Prasat M, Jayadev Gyani PRK, Murti. (2012), Mobile cloud computing : Implications and challenges, ISSN NO.2225-0506, Volume-2, No.7.

[10] Teeshik shon, Jacik cho, Kyusunk Han and Hyohyun Choi. (2014), Toward advanced mobile cloud computing for the internet of things: current issues and future direction, Mobile network and applications 19 (pp. 404-413).

[11] Tzanakaki A, Anastasopoulos M P, Peng S and Rofoee B et al. (2014), A converged network architecture for energy efficient mobile cloud computing, IEEE.

[12] Zohreh Sanari, Saeid Abolfazli, Abdullah Gani, and Muhammad Shiraz, (2012), SAMI: Service based arbitrated multi-tier infrastructure for mobile cloud computing, IEEE, DOI.10.1109/ ICCCCO.2012.6316466.
[13] Weiguang Song and Xiaolong Su, (2011), Review of mobile cloud computing, IEEE, DOI.10.1109/ICCSN.2011.6014374.

[14] Gupta S, and Poonia R. C, Singh V, and Raja L. (2019). Tier Application in Multi-Cloud Databases to Improve Security and Service Availability. In Handbook of Research on Cloud Computing and Big Data Applications in IoT (pp 82-93).

[15] Kim T., et al. (2012). Monitoring and detecting abnormal behaviour in mobile cloud infrastructure, IEEE Network Operations and Management Symposium, Maui, HI, ( pp.13031310).

[16] Poonam S. and Sharma. (May 2015). RESEARCH ARTICLE Mobile Cloud Computing: Its Challenges and Solutions, ISSN 2320-088X IJCSMC, Vol. 4, Issue. 5, ( pp.287 - 293).

[17] Sarode. Rashmi P. And Bhalla, Subhash, ( 2019). Data Security in Mobile Cloud Computing, Proceedings of International conference on Sustainable computing in science, Technology and Management (SUSCOM). Amity University, Rajasthan, Jaipur - India. (pp.26-28).

[18] Rajkumar Buyya, James Broberg, and Andrzej Goscinsky.(2011). "cloud computing principles and paradigms", Wiley India Pvt. Ltd.

[19] Michael Miller, (2008). "cloud computing", 1st Edition, Pearson Education Inc., New Delhi.

[20] Schiller J. (2000). Mobile Communication, Addison Wesley.

[21] William Stallings, (2003). wireless communication and networks, Pearson Education. 